\title{
Factors Contributing to the Problem-Solving Heuristics of Civil Engineering Students
}

\section{Mr. Sean Lyle Gestson, Oregon State University}

Sean Gestson is a recent graduate from the University of Portland where he studied Civil Engineering with a focus in Water Resources and Environmental Engineering. He is currently conducting Engineering Education research while pursuing a doctoral degree in Civil Engineering at Oregon State University. His research interests include problem solving, decision making, and engineering curriculum development.

\section{Dr. Shane A. Brown P.E., Oregon State University}

Shane Brown is an associate professor and Associate School Head in the School of Civil and Environmental Engineering at Oregon State University. His research interests include conceptual change and situated cognition. He received the NSF CAREER award in 2010 and is working on a study to characterize practicing engineers' understandings of core engineering concepts. He is a Senior Associate Editor for the Journal of Engineering Education.

\section{Mr. Matthew Stephen Barner, Oregon State University}

M.S. student at Oregon State University working under Dr. Shane Brown.

Research interests include: engineering education, diffusions of innovation, concerns-based adoption model, conceptual change theory, and earthquake engineering.

\section{Dr. Masoud Ghodrat Abadi, California State University, Sacramento}

Dr. Masoud Ghodrat Abadi is an assistant professor of transportation engineering in Department of Civil Engineering at California State University, Sacramento. Dr. Abadi's research interests lie in the areas of active transportation, traffic control, traffic safety, and engineering education. He teaches graduate and undergraduate classes covering topics such as: Traffic Engineering, Engineering Statistics, and Transportation Planning. Dr. Abadi serves as a member of TRB Standing Committee on Transportation Education and Training (ABG20) and ITE Transportation Education Council.

\section{Dr. David S Hurwitz, Oregon State University}

Dr. David Hurwitz is an Associate Professor of Transportation Engineering in the School of Civil and Construction Engineering at Oregon State University and is the Director of the OSU Driving and Bicycling Simulator Laboratory. Dr. Hurwitz conducts research in transportation engineering, in the areas of traffic operations and safety, and in engineering education, in the areas of conceptual assessment and curriculum adoption. 


\section{Factors Contributing to the Problem-Solving Heuristics of Civil Engineering Students}

Introduction

Problem solvers vary their approaches to solving problems depending on the context of the problem, the requirements of the solution, and the ways in which the problems and material to solve the problem are represented, or representations. Representations take many forms (i.e. tables, graphs, figures, images, formulas, visualizations, and other similar contexts) and are used to communicate information to a problem solver. Engagement with certain representations varies between problem solvers and can influence design and solution quality. A problem solver's evaluation of representations and the reasons for using a representation can be considered factors in problem-solving heuristics. These factors describe unique problem-solving behaviors that can help understand problem solvers. These behaviors may lead to important relationships between a problem solver's decisions and their ability to solve a problem and overall quality of the solution. Therefore, we pose the following research question:

How do factors of problem-solving heuristics describe the unique behaviors of engineering students as they solve multiple problems?

To answer this question, we interviewed 16 undergraduate engineering students studying civil engineering. The interviews consisted of a problem-solving portion that was followed immediately by a semi-structured retrospective interview with probing questions created based on the real time monitoring of the problem-solving interview using eye tracking techniques. The problem-solving portion consisted of solving three problems related to the concept of headloss in fluid flow through pipes. Each of the three problems included the same four representations that were used by the students as approaches to solving the problem. The representations are common ways to present the concept of headloss in pipe flow and included two formulas, a set of tables, and a graph. This paper presents a set of common reasons for why decisions were made during the problem-solving process that help to understand more about the problem-solving behavior of engineering students.

\section{Literature Review}

Solving problems is a common way for studying engineers to learn fundamental engineering concepts and to practice a skill that is typical to the engineering workplace. Problem solving is also a common topic for engineering education research. Previous student focused research in engineering and other STEM related fields has studied textbook utilization, authentic real-world problems, problem-based learning strategies, and representation engagement [1]-[9]. Additional problem-solving research has compared novices (students) and experts (engineering practitioners) to understand the differences in their problem-solving behaviors [10]-[14]. The majority of this research has focused on how problems are solved and what resources or representations are used to solve them. Some anecdotal evidence can be found in research that starts to uncover reasons for why decisions are made during problem solving [15]. Additionally, recent related research with engineering practitioners has focused on the reasons particular problem-solving decisions are made [16], [17]. However, limited research exists on the reasons for why decisions are made, specifically with engineering students. 
While solving problems, students will often engage with representations as a means to gather information or apply an engineering concept. Representations assist in problem solving by organizing content specific to a concept in an attempt to reduce the cognitive load of the problem solver [18]. Problem solvers do not have to rely completely on their recollection of a concept because a representation can present that concept in a simple enough way that allows the problem solver to access the information necessary to solve the problem. Prior research has found that some students prefer certain types of representations over others [15], [19]-[21]. In the 2011 study, Steiff et al. found that college students preferred graphical representations over conceptually equivalent formulaic expressions [15]. Additional studies have also focused on what information within representations students refer to the most and how that relates to the quality of their solution [3], [22], [23]. However, the reasons for using a particular representation is under-explored in engineering education research.

Problem solving research focused on representation use has been completed using both quantitative and qualitative techniques. These studies have used the techniques independently and cooperatively to understand what and how representations are used and what that says about problem solving behavior. Methods for this research include video recordings, timing events, and eye tracking, along with think-aloud and retrospective interviewing techniques [14], [15], [24][26]. Eye tracking is a common technique used to understand representation engagement and is based on the premise that eye movements are correlated with attentional focus and cognitive processing [27]. Previous research with students in STEM related fields using eye tracking techniques focused on the comprehension of multiple molecular representations [15] and the comparison between different formats of representations [3], [10]. Each of these studies combined eye tracking and interview techniques to learn more about how students engage with representations during problem solving. Additionally, related research with engineering practitioners used eye tracking techniques to understand how and what representations were used while using interview techniques to understand more about why those representations were used [17]. This research found unique reasons for problem solving decisions that led to the development of problem solver personas. The combination of eye tracking with retrospective interviews provides additional verification of representation use by using two methods to track that use. The combination of these two methods also gives the interviewer a unique perspective of a problem solvers engagement with each representation that leads to a more thorough set of probing questions in the retrospective interview.

One way to elicit reasons for problem solving decisions and other factors of problem-solving behavior is to provide more than one way to solve a problem. If provided more than one representation, a problem solver's use of a particular representation can be thought of as a way to solve the problem. Their decisions associated with the choice of that representation is related to their behavior as a problem solver. The factors behind these behaviors are similar to problemsolving heuristics. A heuristic is defined as a rule that a problem solver uses to make decisions and reach a solution. The rules can be thought of as a shortcut that helps problem solvers form judgments or make decisions [28]. Previous research focused on heuristics has looked at the formal step-by-step process for solving problems, means end analysis, and schema application [10], [29]-[32]. Problem solvers navigate through problems with different cognitive tool sets that can be used as a way to describe problem-solving behavior. Looking at the reasons and justifications for making decisions during problem solving is under-explored in engineering education research. By eliciting these factors from problem solvers, we hope to present an 
interesting perspective of the thoughts behind important problem-solving decisions. We suggest that engineering educators would benefit from understanding these thoughts as they may lead to better models of problem solving and development.

\section{Methods}

This study is part of a larger study that will compare the problem-solving behaviors of practicing engineers and students using both eye tracking and retrospective interview techniques. The methods used to research and analyze data for this portion of the study are similar to a related studies focused on the problem-solving behavior of practicing engineers [16], [17]. To determine the problem-solving behaviors of engineering students, we developed problems that we believe to be relevant to practicing engineers and engineering students. These problems were developed based on informational interviews with practicing engineers, academic and professional resources, and beta testing with graduate engineering students. This section describes the problem development, participant selection for engineering students, data collection, and data analysis. This study presents the results for 16 engineering students as they solve three problems focused on headloss in pipes.

\section{Problem Development}

Our goal was to develop problems that could be solved with a limited set of representations to understand why decisions were made during problem solving. Additionally, we wanted problems to be relevant to practicing engineers and engineering students. Six informational interviews were conducted with practicing engineers who worked in pipe system design. The goal of these interviews was to determine what types of problems and resources to solve those problems were relevant to practicing engineers. Based on information from these interviews and reference to professional and academic materials associated with pipe system design, we developed eight problems based on the concept of headloss in pipes [33], [34]. Headloss was chosen because it is a fundamental concept for studying engineers that is commonly used by practicing engineers. Each of the eight problems include the same four methods to solve the problem based on common academic and professional representations. These representations include two formulaic expressions (i.e. Darcy Weisbach and Hazen Williams), a graphical representation, and a set of tables that both relate headloss to fluid velocity and pipe diameter. A slide for each problem was created to present the problem statement and the four representations to participants. The four representations are summarized in Table 1 [35]. 
Table 1

Description of the four contextual representations provided to solve each problem

\begin{tabular}{|c|c|c|}
\hline $\begin{array}{c}\text { Contextual } \\
\text { Representation }\end{array}$ & Format & Description \\
\hline $\begin{array}{l}\text { Schedule } 40 \\
\text { Tables }\end{array}$ & Tabular & $\begin{array}{l}\text { Three columns of data describing how headloss per } 100 \text { feet of } \\
\text { Schedule } 40 \text { Steel pipe is related to velocity of fluid flow. Three } \\
\text { pipe sizes included: 4", 6", and 8". }\end{array}$ \\
\hline Hazen Williams & Formula & $\begin{array}{l}\text { Empirical formula that calculates the total headloss in a pipe based } \\
\text { on pipe diameter and length, flowrate, and the Hazen Williams } \\
\text { Coefficient from an included table. }\end{array}$ \\
\hline Headloss Chart & $\begin{array}{l}\text { Tripartite } \\
\text { Graph }\end{array}$ & $\begin{array}{l}\text { Interpreted chart that provides headloss per } 100 \text { feet of pipe based } \\
\text { on plotting the flowrate and diameter of pipe. }\end{array}$ \\
\hline $\begin{array}{l}\text { Darcy } \\
\text { Weisbach }\end{array}$ & Formula & $\begin{array}{l}\text { Empirical formula that calculated the total headloss in a pipe based } \\
\text { on pipe diameter and length, fluid velocity, gravitational constant, } \\
\text { and the friction factor which is interpreted from the Moody } \\
\text { Diagram (provided). The Moody Diagram relates the Relative } \\
\text { Roughness and the Reynolds number to the Friction Factor. }\end{array}$ \\
\hline
\end{tabular}

Note: Reprinted from [35].

Beta testing was completed with two graduate engineering students to test the problems and eye tracking techniques. Based on these two beta tests, three of the eight problems were selected for this study. It was determined after solving three problems, that the results for each graduate student became less unique. This suggests saturation of the data [36]. Additionally, solving eight problems would require a problem-solving interview to last approximately two hours. We believe that three problems provide enough data to meet the goals of this study. Each problem statement is presented in Table 2 . 
Table 2

Description of the three problem statements provided to the students during problem solving

\begin{tabular}{|c|c|c|}
\hline Problem & Problem Statement & Possible Answers \\
\hline 1 & $\begin{array}{l}\text { A } 1000 \mathrm{ft} \text {. length of new unlined } 8 \text { "Schedule } \\
40 \text { steel pipe is being designed to carry water at } \\
\text { a rate of } 550 \text { gpm }\left(1.21 \mathrm{ft}^{3} / \mathrm{s}\right) \text {. What is the total } \\
\text { headloss for this length of pipe? }\end{array}$ & Open Ended \\
\hline 2 & $\begin{array}{l}\text { Which } 8 \text {-inch pipe with a length of } 500 \text { feet } \\
\text { would have the greatest headloss? Assume: } \mathrm{Q}= \\
550 \mathrm{gpm}\left(1.21 \mathrm{ft}^{3} / \mathrm{s}\right) \text {, each pipe is made of new } \\
\text { unlined Schedule } 40 \text { steel, turbulent flow, each } \\
\text { pipe is flowing full, and there is no change in } \\
\text { elevation between point A and point } \mathrm{B} \text {. }\end{array}$ & $\begin{array}{l}\text { A. friction factor, } f_{d}=.015 ; \\
\text { roughness coefficient, } C=160 \\
\text { B. friction factor, } f_{d}=.02 ; \\
\text { roughness coefficient, } C=140 \\
\text { C. friction factor, } f_{d}=.025 ; \\
\text { roughness coefficient, } C=120 \\
\text { D. friction factor, } f_{d}=.03 ; \\
\text { roughness coefficient, } C=110\end{array}$ \\
\hline 3 & $\begin{array}{l}\text { Rank each pipe based on the headloss. Where } 1 \\
\text { is the pipe with the most headloss and } 3 \text { is the } \\
\text { pipe with the least headloss. Assume: } \mathrm{Q}=550 \\
\text { gpm }\left(1.21 \mathrm{ft}^{3} / \mathrm{s}\right) \text {, each pipe is made of new } \\
\text { unlined Schedule } 40 \text { steel, with equal } \\
\text { roughness coefficients, turbulent flow, each } \\
\text { pipe is flowing full, and there is no change in } \\
\text { elevation between point } \mathrm{A} \text { and point } \mathrm{B}\end{array}$ & $\begin{array}{l}\overline{30} \text { 4-inch pipe with a length of } \\
\overline{500} \text { 6-inch pipe with a length of } \\
8 \text {-inch pipe with a length of } \\
1000 \text { feet }\end{array}$ \\
\hline
\end{tabular}

\section{Participants}

Engineering student participants were recruited with campus flyers and an in-class announcements in related engineering courses. Participants were required to have taken a junior level hydraulic engineering course or successfully completed the module on headloss within that junior level hydraulic engineering course. Participation was voluntary and participants were compensated \$20 for the hour-long interview. Data for 16 engineering students were collected. The 16 students were either at a junior or senior class level pursuing a civil engineering degree. Of those 16 students, 11 students were male, and 5 students were female.

\section{Data Collection}

Data was collected during an hour-long problem-solving interview with engineering students. The entire interview consisted of two parts. The first part of the interview consisted of solving the three developed problems while wearing eye tracking equipment to monitor a student's eye glance patterns in real time. We used the Mobile Eye-XG platform from Applied Sciences Laboratories and ET Analysis software from Argus Science to analyze glance patterns. The problems were displayed as a single slide on a computer monitor. A sample slide for one of the 
problems is shown in Figure 1. During this part of the interview, eye glance patterns were also collected for additional analysis in the larger version of this study. However, the scope of this study focuses only on the real time monitoring of the eye glance patterns to assist in the development of robust probing questions based on decisions students make regarding representations during problem solving.

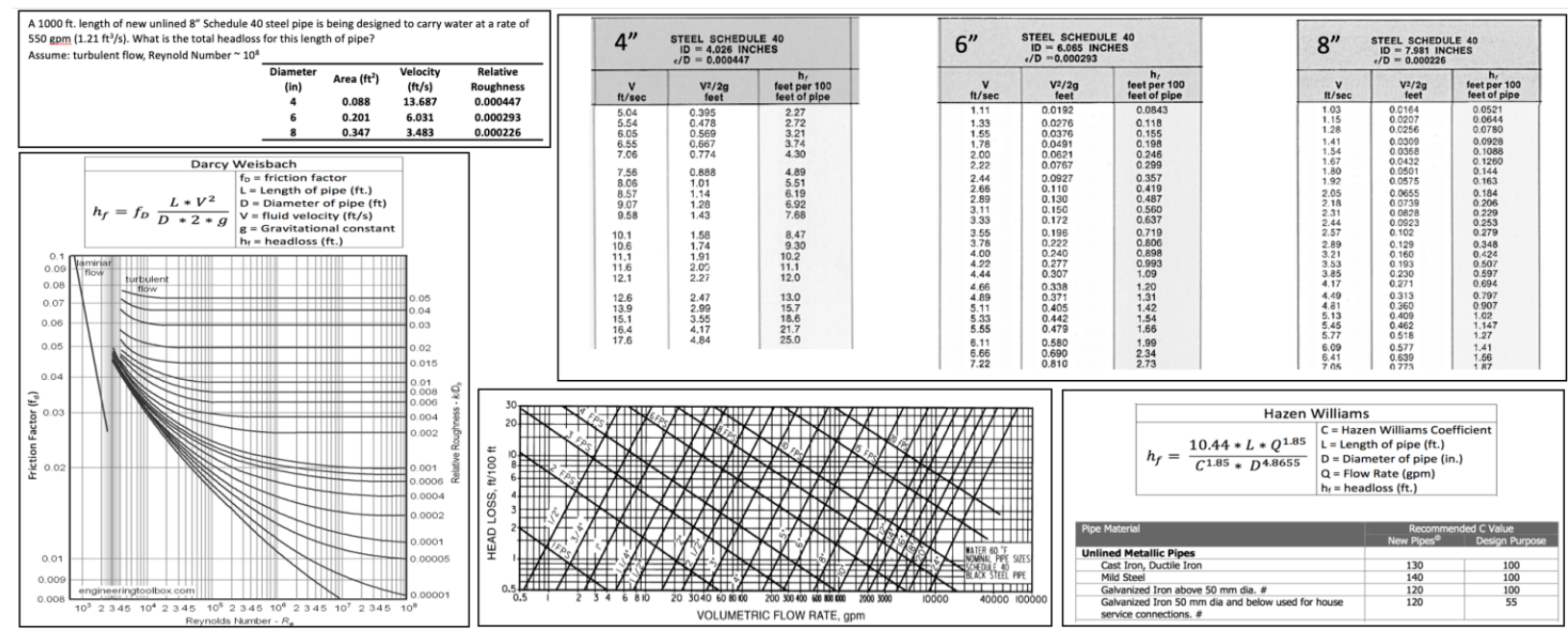

Figure 1: Problem slide for the first problem that is analyzed in this study

The second part of the interview consisted of the semi-structured retrospective interview supplemented with probing questions based on the students' eye glance patterns. The goal of the questions in the retrospective interview were to determine how the problems were solved, what representations were used, and why those representations were used. These questions aimed to expose a problem solvers behavior by determining what factors and motivations guided the problem solver through the solution process. Probing questions based on the observations from the eye tracking data allowed the interviews to be supplemented with questions that could point to specific instances where a problem solver navigated between representations. This would lead to questions like, "Why did you move from $[\mathrm{x}]$ to $[\mathrm{y}]$ and then back to $[\mathrm{x}]$ while solving this problem?". These specific questions provided a unique insight into the problem-solving decisions of the students and produced a more robust narrative about the problem-solving process and specific decisions that may not have been recalled by the participant.

\section{Data Analysis}

Data analysis for this study consisted of the coding of the retrospective interviews. The interviews were transcribed and analyzed in the online qualitative research tool Dedoose ${ }^{\circledR}$ [37]. The retrospective interviews were used to determine which representations were used and how often. Additionally, inductive in-vivo coding techniques were used to capture the participants own words as they justified their reasoning for choosing a particular representation [38], [39]. These justifications describe the factors associated with their problem-solving decision. The codebook used to analyze these transcripts was previously developed during the analysis of the engineering practitioner data set for a related study [17]. This codebook was developed through multiple iterations with intercoder agreement between authors [39]. Code names, definitions, and their application underwent multiple reviews until agreement between researchers was met. A summary of the codebook with definitions and student excerpt examples is shown in Table 3. 
Table 3

In-vivo codes, definitions, and examples from retrospective interviews

\begin{tabular}{|c|c|c|}
\hline Code & Definition & Example Excerpt \\
\hline Speed & $\begin{array}{l}\text { This representation provides } \\
\text { the quickest means to solve } \\
\text { the problem. }\end{array}$ & $\begin{array}{l}\text { "It was the quickest and shortest } \\
\text { solution ... Path, as far as I was } \\
\text { concerned." }\end{array}$ \\
\hline Familiarity & $\begin{array}{l}\text { This representation is more } \\
\text { familiar to use and is often } \\
\text { described as a comfortable } \\
\text { choice. }\end{array}$ & $\begin{array}{l}\text { "Then since I was comfortable with } \\
\text { Darcy and had already known about it, } \\
\text { it seemed fitting, I guess" }\end{array}$ \\
\hline Confidence & $\begin{array}{l}\text { This representation provides a } \\
\text { higher degree of confidence } \\
\text { and trust to solve the problem. } \\
\text { Often described as } \\
\text { representations that are the } \\
\text { least confusing. }\end{array}$ & $\begin{array}{l}\text { "But I think as I was going through, I } \\
\text { just felt confident in my ability to just } \\
\text { plug everything into my calculator and } \\
\text { solve for each pipe diameter." }\end{array}$ \\
\hline Accuracy & $\begin{array}{l}\text { Representation used based on } \\
\text { the level of accuracy that it } \\
\text { provides based on some } \\
\text { engineering judgement of the } \\
\text { student. }\end{array}$ & $\begin{array}{l}\text { "And there would have been a chance } \\
\text { of error with each pipe, and then on top } \\
\text { of that, I would have to change the } \\
\text { diameter of each pipe when solving } \\
\text { using the equation, and there'd just be a } \\
\text { greater chance for messing up..." }\end{array}$ \\
\hline Ease of Use & $\begin{array}{l}\text { Using this representation } \\
\text { requires less work and effort } \\
\text { to solve the problem and is } \\
\text { typically described as easy or } \\
\text { simple. }\end{array}$ & $\begin{array}{l}\text { "Yes, it seemed very simple using the } \\
\text { charts for this problem." }\end{array}$ \\
\hline
\end{tabular}

Results

The first set of results includes a summary of which representations were used and how often. These results are presented in Table 4. Additional results are presented as five individual in-vivo codes from the retrospective interview data analysis. These codes describe common factors associated with problem solving decisions of students. Examples for how each code are justifications for problem solving decisions are presented along with multiple student excerpts. These factors are typically associated with why a student chose a particular representation but, in some instances, a factor is used to describe why they did not choose a representation. A summary of the problem-solving factor frequency amongst the 16 students is presented in Table 5. 
Table 4

Total frequency of representation use for each problem

\begin{tabular}{lcccc}
\hline & Darcy Weisbach & Hazen Williams & Schedule 40 Tables & Figures \\
\hline Problem 1 & 12 & 2 & 1 & 1 \\
Problem 2 & 11 & 5 & 0 & 0 \\
Problem 3 & 9 & 3 & 4 & 0 \\
Total & 32 & 10 & 5 & 1 \\
\hline
\end{tabular}

Table 5

Summary of the problem-solving factor frequency for the 16 students

\begin{tabular}{cccccc}
\hline & Speed & Familiarity & Confidence & Accuracy & Ease of Use \\
\hline Number of Students & 13 & 16 & 12 & 5 & 16 \\
Number of Mentions & 22 & 95 & 34 & 10 & 73 \\
\hline
\end{tabular}

Problem-Solving Factors

Speed

Speed or how fast a problem can be solved is a commonly used factor in the problem-solving process. Of the 16 participants, only 3 did not mention speed when describing why they chose a representation. This factor is mentioned 22 times by 13 students when solving the three problems. The factor speed is often described as quickest, shortest, or some other variation that is related to the time it takes to solve the problem. An example of how speed is used to justify the use of a representation is, "So the Hazen-Williams, which is literally a plug and chug for me and it seemed like the fastest way." Another example that similarly describes speed is, "Definitely, I think you're given a lot of information so you can use that and the stuff that you've already been doing to kind of figure out which context is gonna be the most useful and fastest in solving these problems." In each of these examples, students are concerned with what is the fastest way to solve the problem.

Speed can also be described as, "Because it seemed like the quickest way to find head loss given volumetric flow rate in the problem," and, "Just for, for the sake of time factor." Here the quickest way and the use of the justification of the time factor describe how speed is an important factor when solving these problems. Another example of speed is described when a student says, "Okay. I read the problem. I quickly looked at all the different charts and what they would help me with. Then I saw that the shortest way was just by reading the head loss graph compared to the given flow rate." In this instance, the shortest way is relating how long it will take a student to solve the problem. In all of these instances, the student is motivated to use a representation that does not require as much time as another representation.

Students also use speed as a factor when describing why they did not choose a particular representation. An example of this is, "Then Hazen-Williams, sort of the same thing. I don't use it that much. Also, the C value, now that I'm looking at it, it would've taken me a minute to think about which C value to use." Here the student is not directly mentioning that another 
representation is faster, but instead, mentioning that their use of the Hazen Williams representation as not as fast as another representation. Another example of this is, "HazenWilliams, I actually didn't notice at first because like I said, the Darcy-Weisbach equation I just jumped to that when I saw it. And the charts, they seemed more confusing than they needed to be for this problem, I guess, if that makes sense. Like for me at least, I would have spent more time trying to figure out how to read them than just using the equation I knew and the chart." Here the participant is concerned with the amount of time it would take to figure out the information in the chart and preferred to use an equation-based representation because it would be faster.

Familiarity

Familiarity is the most commonly used factor when choosing a representation. This factor is used at least once by all 16 students for a total of 95 mentions while solving the three problems. The factor familiarity is often described as comfort or related to the problem solvers experience from previous use of a representation. Two examples of this factor are, "I chose Darcy because I have used it the most and so it was the most familiar to me", and "Well, my prior experience revolves mostly around using the Darcy chart and so being familiar with that and having used it so many times, I was ... my intuition led me towards that chart." These are common examples of how this factor is used as a student describes their previous use of the representation and how that relates to its familiarity. Another example of familiarity is described as comfort,

I think with the prior experience, just being able to comfortably find the value of $F$, and then everything else was pretty much given. And then I guess the gravity thing is from prior experience as well. So, knowing what it is in feet per second squared, because that's not given. At least I didn't see it. That's how it guided me.

Here the student described how prior experience is related to their comfort of navigating the representation. The student also describes how this prior experience helps them to understand what units a variable is in and how that guides them through the solution process. Another example of this is, "So I had used it within the last of taking the class, so it was pretty fresh in my mind, and I had a lot of experience using it before. And I felt comfortable using it." Here another student is relating their prior experience with a representation to the comfortability of using it.

Students also used the factor familiarity when describing why they did not choose particular representations. In this example, the student describes why they did not choose three of the representations.

Well the Hazen Williams, we didn't have the coefficient. The C-value for that. That wasn't given. Since we haven't done much work with that in class, I wasn't sure how to solve for that, based off any values given. The tables for the different pipe diameters ... I was unfamiliar with that. Was hesitant to try to figure that out on the spot and then that chart on the bottom ... Bottom middle is just ... An awful lot to look at. Yeah, I've never seen that before so I didn't even know where to start with that.

Each of the three representations is described in some way as being unfamiliar to the student. Having not done much work with a representation, being unfamiliar, and having not seen a 
representation are all variations of limited prior experience and familiarity. This indirectly suggests that the representation the student did choose was based on its familiarity to them. Another example of how less prior experience led to the selection of a representation is, "they were both going to give the same answer, I just know friction factor and I don't have much experience with the roughness coefficient." The student recognizes how the representations will lead to the same answer but chooses the representation they have more experience with.

\section{Confidence}

The factor confidence is related to a student's confidence in a representation or their ability to use that representation. This factor can also be thought of as trust and just knowing a representation will provide the right answer. Confidence is used by 12 students for a total of 34 mentions throughout the solving of the three problems. An example of this factor is, "Just because I knew, I knew I could use those two methods and so I didn't feel the need to try to use any other ones." In this example, the student shows confidence in their ability to use a representation by stating they knew they could use it. Another example of this is, "And I was like, this isn't right. This isn't right. And so, I just gave up and went back to what I knew how to do." Again, the student is justifying their use of a representation based on their knowing how to use it. In this example, another student relates knowing how to use a representation to confidence.

I guess it's really just... I mean they look like they would help, I just didn't... I wasn't confident in my being able to use them in that situation. I knew... I looked in Hazen-Williams and saw that we were given $C$ so I could have done that too and I think I could have been able to because they gave you $Q$ and they gave you $C$ and I think that would have also given me the right answer.

This example describes how a student chooses a particular representation and how their lack of confidence in two of the representations is related to knowing how to use the other representations.

Confidence is also often described indirectly when a student chooses not to use a representation due to a lack of confidence or how confusing the representation is to the student. An example of a lack of confidence in a representation is, "Same reasons before with the head loss and volume metric flow rate chart, I'm not very confident with it. And it didn't seem to provide any information that I really needed." This is similar to how a representation may be confusing to the student and indirectly suggests a lack of confidence. Confusion is commonly mentioned as, "And the steel schedule charts, I don't know, they seemed confusing at the time so I just ignored them." This example shows how the student avoids or ignores the representations they find confusing and have less confidence in.

In some instances, this confusion is related to the confidence of the student's own abilities.

There's lines everywhere. It's kinda hard to read. I'm bad at reading charts anyways. For some reason I've always have been and I feel like I would have just gotten confused in the mess of lines there and then the one above I just 
didn't want to use the energy equation... I've done terrible by reading that chart so I figured I'd go with the other one that didn't require chart reading.

This example shows how a student is not confused about what information the representation is relaying but instead their ability to use the representation. They base their decision on how confident they are in their ability to use an equation rather than a chart or graph format or a representation.

Accuracy

The factor accuracy is the least used factor amongst the students while solving the three problems. This factor is related to how accurate representation will be based on some additional engineering judgement or understanding of the representation from the student. Accuracy is used by 5 of the students for a total of 10 mentions. An example of the factor accuracy is, "But then I was like, "Oh, I'll just use the Darcy-Weisbach and get an exact value." So, I just went there." Another example of accuracy is, "The values weren't exactly matching up, and then I just went to the Darcy-Weisbach to get an exact value. So that was kind of the process with this one." This example shows how a student uses a representation but doesn't agree with the values and decides to use another representation to find a more accurate answer.

Accuracy as judgement also plays a role in the problem-solving process when a student is making sure they understand what information a representation provides. An example of this is, "Yeah, the assumption that the higher the friction factor, the higher the head loss. Just, rather than having any firm mathematical reasoning before checking it with the equations provided." This excerpt relates to judgment because the student is basing their assumptions on some prior knowledge or understanding and using that as a check to make sure they can use the equations provided.

The factor accuracy is also used when describing why a representation is not used. In this case a representation may not be used because it does not provide an accurate enough answer based on the students' interpretation of the representation. An examples of this is,

Then in my head I was like, "Oh, this is kind of guessing, too." I forgot that you kinda had to guess with this table, too. I was like, "Oh well." So, I just chose a friction value and then just ... You know your length, your velocity, your diameter, and your G...looked at the 8-inch Schedule 40 table. Then that was where I was like, "Well, there's not really an exact value. I could kinda guess." Yeah, I could kinda guess and then multiply that H by 10 to get my 1,000-feet length of pipe."

Here the student describes how they do not prefer to use a table based on the need to guess or pick values instead of calculating them with an equation. The need to guess is not accurate enough for the student.

Another example of how using charts leads to less accurate answers is described as the chance for error.

I would have had to make an assumption there at ten to the eight and then find a friction factor and there's a chance for error in doing that in reading the chart. 
And there would have been a chance of error with each pipe, and then on top of that, I would have to change the diameter of each pipe when solving using the equation, and there'd just be a greater chance for messing up, I felt like.

This chance for error caused the student to use a different representation in an attempt to get a more accurate solution. The student was concerned about the number of ways a particular representation could contribute error to the solution and therefore chose a different representation.

\section{Ease of Use}

The factor ease of use describes the simplicity of using a representation. This factor is the second most commonly used factor. Ease of use is used by all 16 students and mentioned 73 times when describing their solutions to the three problems. Ease of use is often described as less complicated, less work, laziness, and straightforward. Some examples for how ease of use is used are, "Yes, it seemed very simple using the charts for this problem", "I just didn't wanna look through- laziness, for lack of a better word", and "To calculate that out I would've had to do more work, rather than just pulling it off the chart". Each of these examples describe the various ways ease of use is used as a means to justify why a representation is used.

One of the most common ways to describe ease of use is the word simple. In many instances, students rely on a representation because of its simplicity when working towards a solution. Some additional examples of this are, "...just on the simple fact that equation based, I think, is simpler than the charts", "That's why I checked with the two simplest methods rather than using one of the more calculation dependent methods", and "So, yeah, simplicity definitely played a factor in using the Darcy Weisbach". This examples further show how a student is motivated to use a representation that is simpler than the other representations.

Ease of use is also described by a common phrase, "plug and chug". In these instances, students are referring to the simple nature of putting in numbers and working through the calculations. This is something common when using equations while problem solving. Some examples of this are, "I guess so, it was just kind of a plug and chug kind of thing" and "I thought they were both pretty simple plug and chug so I did them both just to compare to each other". Additionally, ease of use is described as straightforward. "I thought that that would be the easiest, most straightforward equation for the information given". Here the student uses straightforward as another way to say easiest. In some instances, the student uses multiple descriptors for ease of use in their justification for representation use. "Hazen-Williams, everything was basically plug and chug, whereas the Darcy-Weisbach ... Let's see. I don't know. I think the Hazen-Williams just seemed more straightforward in my mind at the time."

Much like the other factors, ease of use is also used indirectly when describing why a representation is not used. An example of this is, "More computation and more difficult exponents to punch in." Here the student is justifying their use of a particular representation due to less computation and less difficulty. Another similar example of this is, "Less calculations. This had more interpretation." Here the student similarly relies on a representation that requires less work. 


\section{Discussion}

The students in this study have unique ways of solving the problems that rely on a common set of factors. Even though each of these factors have been described as independent, there are common combinations that suggest that some of the factors are related. The most common overlap of factors is between familiarity, ease of use, and speed. In some instances, students describe their selection of a representation as, "sticking with what I know what was the simplest and easiest for me just because of familiarity". This is similar to, "Simple as I can make it, seeing the fastest I can get it done". In both of these examples the students have described more than one factor when justifying their use of a representation. Even though this problem-solving behavior is not exhibited by every student, it suggests that these factors may be related to each other and can be used together to motivate and guide a student through the solution process. These examples show that familiarity with a representation imply that a student can more quickly and simply solve a problem. Further exploring how these factors are related could help to explain more about the underlying factors for why problem-solving decisions are made.

The results from this study also show how familiarity is a common and important factor when choosing a representation. This is similar to previous research which has shown that professionals rely on experiential knowledge when solving problems [14], [40], [41]. The students in this study relied more on their familiarity with a representation than any other factor. As previously discussed, familiarity is also related to other factors such as speed and ease of use. This further suggests how important familiarity or experience is when solving problems. Future research could further examine how familiarity and experiential knowledge is related to problem solving decisions.

The results also show that representation use varied amongst students. However, a majority of the problems were solved with the Darcy Weisbach representation. During the solution to the three problems, students used Darcy Weisbach 32 times. This suggests that students preferred the Darcy Weisbach representation over other representations. Additionally, by combining the representation use of the two formulaic representations (i.e. Darcy Weisbach and Hazen Williams) it was discovered that the formulas were preferred 8 to 1 over the graphical and tabular representations. This is contrary to previous research which showed that chemistry students preferred graphical and visual representations over conceptually equivalent formulaic representations [15]. We do not suggest that the previous results are invalid, however we suggest that the context and concepts being presented in a representation may be related to which representations are preferred. Further research could look at the differences between what concepts and contexts are presented and how that plays a role in representation preference.

The results from this study help to provide a more holistic understanding of the problem-solving process and behavior of students. We do not suggest that every problem solver applies these factors when problem solving but we do suggest that they are common in the solution process of engineering students. Understanding why a student chooses a representation or makes problem solving decisions could lead to better problem development and the improvement of instructional methods. This data can also be used to compare the behaviors of novices (students) and experts (practitioners). If engineering practitioners provide similar factors for problem solving decisions, it may be important to understand how those factors compare to the factors of students.

Assignments or lessons could be tailored to the benefits and disadvantages of solving problems 
using various methods and how and when these factors are used. Students could be asked to provide additional justifications and reasons for their decisions that can be used for evaluation or discussion in assignments or exams. These discussions could include examples of problemsolving factors of practicing engineers that could help provide more authentic problem-solving experiences for students. Comparing these results can lead to a better understanding of the similarities and differences between novice and expert problem-solving behavior.

\section{Limitations}

A limitation of this study is the test like context of the problem-solving interview while wearing eye tracking glasses. Each participant wears a set of glasses with a wire connected to a data collection device. Wearing these glasses while also solving problems much like a test is likely to contribute to additional test like stress on a participant. Stress of other effects from this problemsolving context may have an influence on which representation is used and the factors associated with a problem solver's behavior. Future research could focus on the differences in behavior with varied problem-solving contexts and how that affects which representations are used.

Additionally, demographic information such as class standing, internship or outside work experience was not collected on each student participant which limits the analysis for any correlation between these factors. Future research could focus on the effect of additional experience beyond the classroom of students.

\section{Conclusion}

The purpose of this research was to determine what factors of problem-solving heuristics students use to solve problems with multiple representations. The research helps to explain why decisions are made during the problem-solving process as most problem-solving research only addresses how and what. The real-time monitoring of the problem-solving interviews with eye tracking techniques led to the development of robust probing questions in the retrospective interviews. The interviews further described the problem-solving process of students that uncovered the factors associated with why problem-solving decisions were made. Of the five problem-solving factors presented in this study, familiarity is the most used by all 16 students with a total of 95 mentions. Ease of use is the second most used factor amongst all students with 73 mentions. Speed and confidence are used by 13 and 12 of the 16 students with 22 and 34 mentions, respectively. The least used factor is accuracy which was used by 5 students for a total of 10 mentions. Students also prefer formulaic expressions of representations compared to tabular or graphical representations with the Darcy Weisbach equation being the most used representation. The results show that students use a common set of problem-solving factors that motivate and guide the them through the solution process. This research can help engineering educators to more holistically understand the problem-solving process of engineering students. 
References

[1] D. Bolden, P. Barmby, S. Raine, and M. Gardner, "How Young Children View Mathematical Representations: A Study Using Eye-Tracking Technology," Educ. Res., vol. 57, no. 1, pp. 59-79, 2015.

[2] A. Elby, "What students' learning of representations tells us about constructivism," $J$. Math. Behav., vol. 19, no. 4, pp. 481-502, 2000.

[3] M. Hill and M. D. Sharma, "Students' Representational Fluency at University: A CrossSectional Measure of How Multiple Representations are Used by Physics Students Using the Representational Fluency Survey," Eurasia J. Math. Sci. Technol. Educ., vol. 11, no. 6, pp. 1633-1655, 2015.

[4] R. Kozma, E. Chin, J. Russell, and N. Marx, "The Roles of Representations and Tools in the Chemistry Laboratory and Their Implications for Chemistry Learning," J. Learn. Sci., vol. 9, no. 2, pp. 105-143, 2000.

[5] C. S. Lee, N. J. Mcneill, E. P. Douglas, M. E. Koro-Ljungberg, and D. J. Therriault, "Indispensable Resource? A Phenomenological Study of Textbook Use in Engineering Problem Solving," J. Eng. Educ., vol. 102, no. 2, pp. 269-288, 2013.

[6] E. Hamilton, R. Lesh, F. Lester, and M. Brilleslyper, "Model-Eliciting Activities (MEAs) as a Bridge Between Engineering Education Research and Mathematics Department of Mathematical Sciences," Adv. Eng. Educ., vol. 1, no. 2, pp. 1-25, 2008.

[7] M. Cirstea, "Problem-Based Learning (PBL) in Microelectronics*," Int. J. Eng. Educ., vol. 19, no. 5, pp. 738-741, 2003.

[8] P. A. Johnson, "Problem-Based, Cooperative Learning in the Engineering Classroom," $J$. Prof. Issues Eng. Educ. Pract., vol. 125, no. 1, pp. 8-11, 1999.

[9] C. McIntyre, "Problem-Based Learning as Applied to the Construction and Engineering Capstone Course at North Dakota State University," Proc. - Front. Educ. Conf., vol. 2, 2002.

[10] P. B. Kohl and N. D. Finkelstein, "Patterns of multipe representation use by experts and novices during physics problem solving," Phys. Rev. Spec. Top. - Phys. Educ. Res., vol. 4, no. 1, pp. 1-13, 2008.

[11] H. Jarodzka, K. Scheiter, P. Gerjets, and T. van Gog, "In the eyes of the beholder: How experts and novices interpret dynamic stimuli," Learn. Instr., vol. 20, no. 2, pp. 146-154, 2010.

[12] R. B. Kozma and J. Russell, "Multimedia and Understanding: Expert and Novice Responses to Different Representations of Chemical Phenomena," vol. 34, no. 9, pp. 949968, 1997.

[13] S. Kim, V. Aleven, and A. K. Dey, "Understanding Expert-Novice Differences in Geometry Problem-Solving Tasks," Proc. Ext. Abstr. 32nd Annu. ACM Conf. Hum. factors Comput. Syst. - CHI EA '14, pp. 1867-1872, 2014.

[14] C. J. Atman, R. S. Adams, M. E. Cardella, J. Turns, S. Mosborg, and J. Saleem, "Engineering Design Processes: A Comparison of Students and Expert Practitioners," J. Eng. Educ., vol. 96, no. 4, pp. 359-379, 2007.

[15] M. Stieff, M. Hegarty, and G. Deslongchamps, "Identifying Representational Competence With Multi-Representational Displays," Cogn. Instr., vol. 29, no. 1, pp. 123-145, 2011.

[16] M.-G. Abadi, S. L. Gestson, S. Brown, and D. Hurwitz, "Traffic Signal Phasing ProblemSolving Rationales of Professional Engineers Developed from Eye-Tracking and Clinical Interviews," in 98th Transportation Research Board Annual Meeting Compendium, 2018. 
[17] S. L. Gestson, M. S. Barner, M.-G. Abadi, D. S. Hurwitz, and S. A. Brown, "Problem Solving Personas of Civil Engineering Practitioners using Eye Tracking Techniques," Int. J. Eng. Educ., p. Manuscript submitted for publication., 2019.

[18] S. K. Card, J. D. Mackinlay, and B. Shneiderman, "Readings in Information Visualization: Using Vision to Think," in Information Display, 1999.

[19] L. Mason, P. Pluchino, M. C. Tornatora, and N. Ariasi, “An Eye-Tracking Study of Learning From Science Text With Concrete and Abstract Illustrations," J. Exp. Educ., vol. 81, no. 3, pp. 356-384, 2013.

[20] D. E. Meltzer, "Relation between students' problem-solving performance and representational format," Am. J. Phys., vol. 73, no. 5, pp. 463-478, 2005.

[21] J. Zhang, "The Nature of External Representations in Problem Solving," Cogn. Sci., vol. 21, no. 2, pp. 179-217, 1997.

[22] T. J. Moore, R. L. Miller, R. A. Lesh, M. S. Stohlmann, and Y. R. Kim, "Modeling in Engineering: The Role of Representational Fluency in Students' Conceptual Understanding," J. Eng. Educ., vol. 102, no. 1, pp. 141-178, 2013.

[23] M. J. Nathan, A. C. Stephens, K. Masarik, M. W. Alibali, and K. R. Koedinger, "Representational fluency in middle school: A classroom study," Proc. Twenty-Fourth Annu. Meet. North Am. Chapter Int. Gr. Psychol. Math. Educ. Vol. 1, pp. 462-474, 2002.

[24] M. Cook, E. N. Wiebe, and G. Carter, "The Influence of Prior Knowledge on Viewing and Interpreting Graphics With Macroscopic and Molecular Representations," Sci. Educ., vol. 92, no. 5, pp. 848-867, 2008.

[25] M. D. Patrick, G. Carter, and E. N. Wiebe, "Visual Representations of DNA Replication: Middle Grades Students' Perceptions and Interpretations,” J. Sci. Educ. Technol., vol. 14, no. 3, pp. 353-365, 2005.

[26] C. Venters and L. Mcnair, "Learning Statics: A Cognitive Approach," ASEE Southeast Sect. Conf., no. 0218, pp. 1-10, 2010.

[27] M. L. Lai et al., "A review of using eye-tracking technology in exploring learning from 2000 to 2012," Educ. Res. Rev., vol. 10, no. 88, pp. 90-115, 2013.

[28] A. H. Schoenfeld, "Learning To Think Mathematically : Sense-Making in Mathematics," Handb. Res. Math. Teach. Learn., pp. 334-370, 1992.

[29] A. H. Schoenfeld, "Metacognitive and epistemological issues in mathematical understanding," in Teaching and Learning Mathematical Problem Solving: Multiple Research Perspectives, 1985.

[30] M. Lorenzo, "The Develepment, Implementation, and Evaluation of a Problem Solving Heuristic," Int. J. Sci. Math. Educ., vol. 3, no. 1, pp. 33-58, 2005.

[31] M. T. H. Chi, P. J. Feltovich, and R. Glaser, "Categorization and Representation of Physics Problems by Experts and Novices," Cogn. Sci., vol. 5, no. 2, pp. 121-152, 1981.

[32] P. Pande and S. Chandrasekharan, "Representational competence: towards a distributed and embodied cognition account," Stud. Sci. Educ., vol. 53, no. 1, pp. 1-43, 2017.

[33] Hydraulic Institute Engineering Data Book, 2nd ed. Hydraulic Institute, 1990.

[34] F. Morse, Hydraulic Handbook. Colt Industries, 1988.

[35] S. L. Gestson, B. D. Lutz, S. A. Brown, M. S. Barner, D. S. Hurwitz, and M. G. Abadi, "Developing an Understanding of Civil Engineering Practitioner Problem-solving Rationale Using Multiple Contextual Representations," 2018.

[36] P. I. Fusch and L. R. Ness, "Are We There Yet? Data Saturation in Qualitative Research," 2015. 
[37] "Dedoose," SocioCultural Research Consultants, LLC. Los Angeles, CA, 2018.

[38] J. Saldana, "Coding manual for qualitative researchers," Sage J., pp. 0-42, 2015.

[39] M. B. Miles, M. A. Huberman, and J. Saldaña, Qualitative Data Analysis. A Methods Sourcebook. 2014.

[40] D. Hurwitz, S. Brown, M. Islam, K. Daratha, and M. Kyte, "Traffic Signal System Misconceptions Across Three Cohorts," Transp. Res. Rec. J. Transp. Res. Board, vol. 2414, no. 2414, pp. 52-62, 2014.

[41] D. Jonassen, J. Strobel, and C. Lee, "Everyday Problem Solving in Engineering: Lessons for Engineering Educators," J. Eng. Educ., vol. 9, no. 2, pp. 139-151, 2006. 